AL.2.1998-t7

c. 2

Forest

Development

Research

\begin{tabular}{lllllll}
\hline$P$ & $R$ & $O$ & $G$ & $R$ & $A$ & $M$
\end{tabular}

Manning Diversified Forest Products

Research Trust Fund

MDFP 22/95

Assessment of Spruce Budworm Impacts in the Hawk Hills Management Area

1996/97 Update

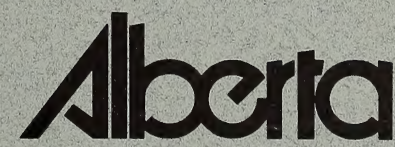

ENVIRONMENTAL PROTECTION 


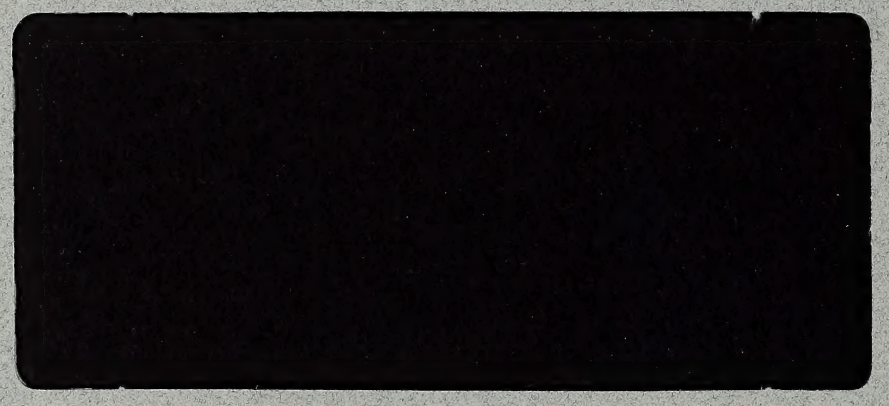




\section{Manning Diversified Forest Products \\ Research Trust Fund \\ MDFP 22/95}

Assessment of Spruce Budworm Impacts in the Hawk Hills Management Area

1996/97 Update

\section{June 1997}

By Drs. David Watson, Jan Volney and Peter Boxall Northern Forestry Centre

Canadian Forest Service Edmonton, Alberta Canada 
Digitized by the Internet Archive in 2016

https://archive.org/details/assessmentofspru00wats 


\title{
Assessment of spruce budworm impacts in the Hawk Hills Management Area
}

\author{
David Watson \\ Jan Volney \\ Peter Boxall
}

Northern Forestry Centre

Canadian Forest Service

Edmonton Alberta 


\section{DISCLAIMER}

The study on which this report is based was funded by the Manning Diversified Forest Products Research Trust Fund, which is a component of the Government of Alberta's Environmental Protection and Enhancement Fund. The views, statements and conclusions expressed and the recommendations made in this report are entirely thos of the author(s) and should not be construed as the statements, conclusions, or opinions of members of the Manning Diversified Forest Products Research Trust Fund Committee, the Government of Alberta, or the Alberta Forest Research Advisory Council. The conclusions in this document are tentative as this reports on work in progress. The conclusions should not be cited as they are subject to change pending completion of the project. 


\begin{abstract}
The economic effect of spruce budworm infestations on white spruce stands was examained. Various projections of the magnitude of the damage caused by the infestation were made to determine probable growth and yield under different conditions. These conditions included contrast the result of spraying of BTK versus non-spraying, and the pre-emptive spraying of BTK versus reactive spraying. In addition, the effect on yields of increased tree mortality due to defoliation was investigated. Economic valuation of the damaged caused by spruce budworm infestations was carried out through the use of cost-benefit analysis, and the net present value technique. Results show there there is a measureable and long term effect on growth and yield in white spruce stands. The cost benefit analysis reveals that monetary savings are possible both in the short and long terms from spraying. Monetary losses from the infestation are lower in the reactive spray scenario than in the no-spray scenario, and lowest losses are achieved by pre-emptive spraying. Increased mortality effects increases losses in all cases.
\end{abstract}




\section{ACKNOWLEDGEMENTS}

We thank the Manning Diversified Forest Products Integrated Technical Sub-committee for supporting this work philosophically and financially. We are grateful to the Land and Forest Service of Alberta Envrionmental Protection and its predecessor (the Alberta Forest Service) for initiating the spruce budworm control experiment and supporting this work in its earliest years. We are also grateful to Alberta Enviromental Protection for providing accommodation and sustenance, the use of equipment and encouragement while conducting work at Manning. The staff at the Forest Pest Management unit, the Peace River Office and at the Manning Tanker Base provided invaluable logistic and materiel support for which we are grateful. Dr. Shongming Huang of the Forest Management Division was very helpful in guiding us through the intracacies of growth and yield calculations.

Andu Yohannes supervised the sprcue budworm collections and the other field work involved in the earliest years and Brad Tomm supervised the work involved in cutting the trees, preparing the disks and X-radiographs and analysing the images. Robert Lucas and John Brace did much of the processing and counting of insects. In addition we note the help of the many summer students that participated in field sample processing for population estimates. Without these able individuals we would not have been able to compile the data on this project and are grateful for their assistance. 


\section{TABLE OF CONTENTS}

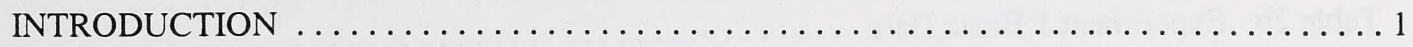

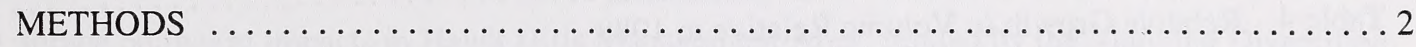

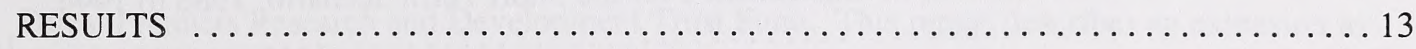

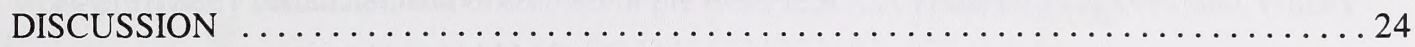

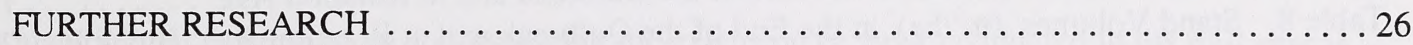

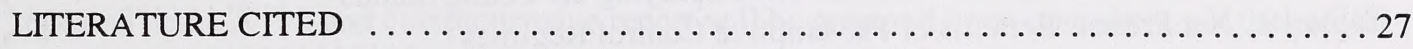

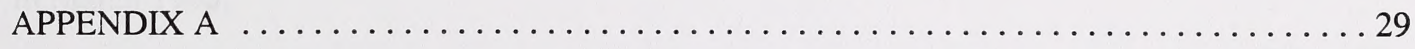

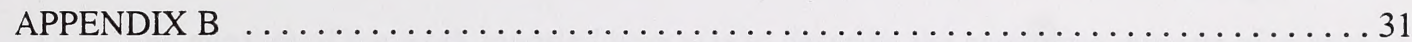

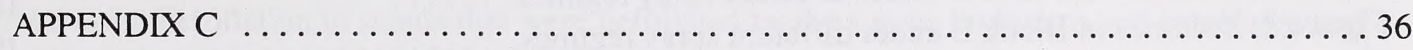




\section{List of Tables}

Table 1. Experimental Design and Project Plot Numbers $\ldots \ldots \ldots \ldots \ldots \ldots \ldots \ldots \ldots \ldots$

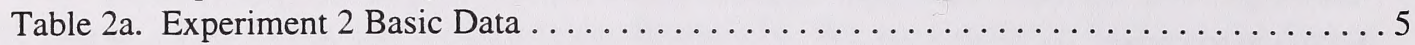

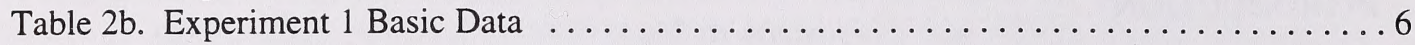

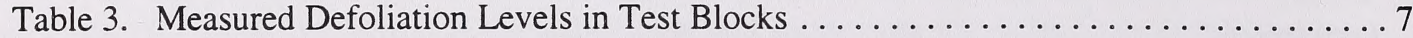

Table 4. Relative Growth in Volume Relative to $1988 \ldots \ldots \ldots \ldots \ldots \ldots \ldots \ldots \ldots \ldots$. . . . . . . 9

Table 5. Stand Volume ( $\mathrm{m}^{3} / \mathrm{ha}$ ) in Experiment 1 for the Short Term Scenario; 1988 to 1994.

Table 6. Stand Volume $\left(\mathrm{m}^{3} / \mathrm{ha}\right)$ in Experiment 2 for the Short Term Scenario; 1988 to 1994

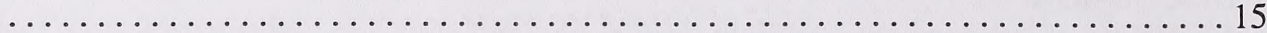

Table 7. Stand Volumes $\left(\mathrm{m}^{3} / \mathrm{ha}\right)$ at the End of the Outbreak and at Rotation Age ...... 17

Table 8. Stand Volumes $\left(\mathrm{m}^{3} / \mathrm{ha}\right)$ at the End of the Outbreak and at Rotation Age: Block B .20

Table 9. The Benefits and Costs of Reactive Spraying on Young Stands . . . . . . . . . . 23

Table 10. Net Present Benefits of Pre-emptive Control Regimes . . . . . . . . . . . . . . 24

List of Figures

Figure 1. Volumes in Block $\mathrm{D}$ under different spray regimes. $\ldots \ldots \ldots \ldots \ldots \ldots \ldots \ldots$

Figure 2. Volumes in Block $E$ under different spray regimes. . . . . . . . . . . . . 19

Figure 3. Volumes in Block $B$ under different spray regimes. $\ldots \ldots \ldots \ldots \ldots \ldots \ldots \ldots \ldots$ 


\section{INTRODUCTION}

This is the second progress report on work conducted on a study entitled "Assessment of spruce budworm impacts in Hawk Hills Management Area" funded by the Manning Diversified Forest Products Research and Development Trust Fund. This report describes an extension to work previously conducted and described in previous reports (Volney 1991, 1992 and Volney and Watson 1996) and an attempt has been made to avoid duplication in reporting. Thus, only material that is pertinent to understanding the extension of work conducted in the past year is repeated here. A full and comprehensive report will be prepared upon completion of the project in March 1998.

The purpose of the work reported here was to describe the economic impacts of spruce budworm defoliation to stands that were defoliated by the spruce budworm and protected with Bacilus thuringiensis var kurstaki (BTK) applied with various strategies in mind. Unprotected stands served as controls. Two treatment strategies were investigated: reactive spraying in stands that were damaged by severe budworm defoliation for at least two years prior to spraying and proactice spraying in which stands were prevented from ever becoming severely defoliated. The net economic benefit of these strategies are estimated and discussed in the present report. 


\section{METHODS}

In order to measure the effect of a spruce budworm outbreak on the value of wood fiber production of a stand, information on stand growth and yield, with and without budworm effects is required. A knowledge of the economic value of fiber and the cost associated with the control program used to reduce the effects of the insect are also required to estimate costs and benefits. MacLean and Erdle (1984) outline a similar procedure for a hypothetical fir forest, but do not describe economic measures. Because the benefits and costs of budworm control operations accrue at different times, the net economic benefits are calculated by discounting these values to a common year: 1990 .

As described by Volney and Watson (1996), two experiments were conducted on white spruce stands in the Hawk Hills Management Area. The first experiment involved three relatively young stands: designated E,D, and F that were about 60 years old. Here the outbreak was permitted to develop and severe defoliation occurred before spraying BTK on 2 of the 3 stands was undertaken. In this case the third stand was used as a control so that the effect of spraying could be assessed. This experiment was used to evaluate the merits of an operational control tactics where measures to influence the outbreak were enacted after the outbreak was well established.

The second experiment involved three older stands (roughly 100 years old). In this case, insect control measures were used on two of the stands (A, B), one in which the damage to foliage was permited to become severe (A) before spraying and the other (B) in which protection was applied before severe defoliation developed. This experiment was designed to contrast the net present benefits from reactive and pre-emptive control policies. A third unsprayed stand (C) in this group was to be used as a control. However, it could not be used because its site index was too dissimilar from the other two. Projections based on yield tables were used where contrasts with the undamaged condition were required. 
Each experiment involved two scenarios and two different time periods. One time period involved the measurement of growth in the six years following an infestation. The second time period involved a forecast of the growth in volume of the stand to the rotation period. In each case the analysis involved a comparison of volume growth that would have occurred without budworm damage with growth involving budworm effects. To extend the results of the study for the duratation of the outbreak, the second of the time periods, two scenarios were developed; one involved assessing stand volume with extra mortality due to the effect of budworm and one without. This approach was necessary because we have not made observations for the duration of a full outbreak.

In the initial phases of this study, the test plots were established and the growth and yield of white spruce in these plots was evaluated. A review of existing literature was conducted on the effects of spruce budworm defoliation on growth and yield. Furthermore, literature relating to the economic effects of the budworm on forest yield was examined and discussions with Manning Diversified and Alberta Land and Forest Service (LFS) personnel were conducted to collect in formation on the costs of control measures and the gross revenues derived from harvesting white spruce stands in the study area.

Standardized growth and yield tables for the province published by AFS (1985) were used to model general growth and yield of white spruce in the Hawk Hills area. However, a number of the formulas in that report were unclear or incorrect. This caused some confusion and errors during attempts to re-create growth and yield tables. In discussions with LFS staff, the formulas were amended and an example table for a good site of white spruce was prepared. These are shown in Appendix A. These growth and yield tables require a knowledge of the Site Index (SI). We used information on height of trees at age 50 to determine the SI. This data was obtained from 96 trees felled within the 24 plots (Volney and Watson 1996).

Three test blocks were established in the Hawk Hills area in 1990 that covered areas affected by an outbreak initiated in 1988. Each of these blocks contained four 0.04 hectare plots for a total of 12 test plots. At the same time, LFS Permanent Sample Plots were set up adjacent to 
the 12 plots. Another set of three test blocks (each containing 4 plots) was initiated in 1991. Here one of these blocks (B) did not show signs of the spruce budworm defoliation. Further information on the experimental design, and the entomological measurements is available in Volney $(1992,1993)$. The set up of the blocks, and spray regime is shown in Table 1.

\begin{tabular}{|l|l|l|l|l|}
\hline \multicolumn{5}{|c|}{ Table 1. Experimental Design and Project Plot Numbers } \\
\hline Block & $\begin{array}{c}\text { Plot } \\
\text { numbers }\end{array}$ & $\begin{array}{c}\text { Year plot } \\
\text { initiated }\end{array}$ & $\begin{array}{c}\text { Permanent Sample } \\
\text { Plots }\end{array}$ & \multicolumn{1}{c|}{ Spray regime } \\
\hline \multicolumn{5}{|c|}{ Experiment 2: Reactive versus pre-emptive spraying } \\
\hline A & $13-16$ & 1991 & none & 50 BIU' twice in 1991 \\
\hline B & $17-20$ & 1991 & none & 50 BIU twice in 1991 \\
\hline C & $21-24$ & 1991 & none & none \\
\hline & Experiment 1: Growth comparison with and without spraying \\
\hline D & $5-8$ & 1990 & $495,496,497,498$ & $\begin{array}{l}30 \text { BIU once in } 1990 \\
25 \text { BIU twice in } 1991\end{array}$ \\
\hline E & $1-4$ & 1990 & $466,467,468,471$ & $\begin{array}{l}30 \text { BIU once in } 1990 \\
25 \text { BIU once in } 1991\end{array}$ \\
\hline F & $9-12$ & 1990 & $472,473,474,494$ & none \\
\hline
\end{tabular}

${ }^{1} \mathrm{BIU}$ is Billion International Units of BTK. Normal operational spraying for northern Alberta is 25.4 BIU in two separate applications within the same year.

\section{Growth and Yield Estimation}

Three methods to determine stand growth were compared. First, the height at age 50 for 16 felled trees within each block was used for an unmanaged, even-aged, single species stands of white spruce to determine the block's SI and thus their volumes. Second, the same height measurements were used in computing the volumes for the white spruce component of unmanaged mixed-wood stands. Third, height and diameter at breast height (DBH) measurements of all white spruce within each plot were used to calculate individual tree volumes and combined with stem densities to obtain volumes per hectare. In consultation with Huang 
(LFS), the resulting estimates were compared, corrected for plot conditions, and volumes obtained using the SI of single species white spruce. These volumes were selected as the most appropriate measure of stand volume. It is important to note that in all stands these procedures resulted in a lower SI than the height at age 50 would have given. Thus, the estimated stand volumes are conservative (underestimates).

The rotation age of a stand is normally calculated by foresters as the age at which the Mean Annual Increment (MAI) and Periodic Annual Increment (PAI) are equal. MAI is the average annual increment over the life span of the stand or tree, calculated by dividing the volume by the age. PAI is the difference in volume during a specific period: in this case we chose 10 year divisions used in the growth and yield tables. The age at which the MAI and PAI graphs intersected was chosen as the rotation age. The pertinent productivity information for the six blocks is shown in Tables $2 \mathrm{a}$ and $2 \mathrm{~b}$.

\begin{tabular}{|l|c|c|c|c|}
\hline \multicolumn{5}{|c|}{ Table 2a. Experiment 2 Basic Data } \\
\hline & Combined & \multicolumn{3}{c|}{ Average Block Features } \\
\hline & A-B-C & A & B & C \\
\hline Site Index (m @ 50 y) & 13.3 & 16.1 & 13.4 & 10.5 \\
\hline Age (in 1990) (y) & 99.5 & 101.8 & 90.1 & 107.4 \\
\hline Age at MAI maximum 1 (y) & 110.0 & 100.0 & 110.0 & 130.0 \\
\hline MAI/PAI rotation age (y) & 115.0 & 100.0 & 114.0 & 139.0 \\
\hline Volume at rotation age (m ${ }^{3} /$ ha) & 309.7 & 330.0 & 309.3 & 294.5 \\
\hline
\end{tabular}

${ }^{1}$ MAI max measured from tables with 10 year growth increments. 


\begin{tabular}{|l|c|c|c|c|}
\hline \multicolumn{5}{|c|}{ Table 2b. Experiment 1 Basic Data } \\
\hline & Combined & \multicolumn{3}{|c|}{ Average Block Features } \\
\hline & D-E-F & D & E & F \\
\hline Site Index (m @ 50 y) & 14.2 & 16.5 & 15 & 12 \\
\hline Age (in 1990) (y) & 64.7 & 67.8 & 63.2 & 63.1 \\
\hline Age at MAI maximum ${ }^{1}(\mathrm{y})$ & 100 & 90 & 100 & 120 \\
\hline MAI/PAI rotation age (y) & 109 & 96 & 104 & 125 \\
\hline Volume at rotation age (m $\left.{ }^{3} / \mathrm{ha}\right)$ & 316.2 & 328.5 & 319 & 302.3 \\
\hline
\end{tabular}

${ }^{1}$ MAI max measured from tables with 10 year growth increments

Discussions with LFS personnel in Peace River (Carl Peck, pers comm 1996) about white spruce rotations suggests that our calculated values are "about" right. The average rotation age for that general area is 105 years. They have always used the point of peak MAI for their rotations. They also set the rotation for a whole FMA at one time, and then establish the cutting plan within the FMA. There are also other factors taken into consideration, such as the market price of saw logs when involved. In practice, however, the age at which the stand is cut is generally older than the rotation age. Though rare, it has occasionally happened that salvage harvesting took place on infested areas near the rotation age. It depends as much as anything on the cutting plan, and the capacity of the receiving plant to process the wood.

\section{Analysis of reduced growth from budworm}

The history of defoliation in these plots is shown in Table 3. A basic assumption of this study, substantiated by the tree ring record, is that the budworm outbreaks became severe in 1988 for the 5 Blocks where their presence was detected in 1989. However, Block B did not show signs of defoliation at the time of setup. These observations allow the assessment of two different control treatments mentioned above (e.g. reactive and pre-emptive). In the first experiment Blocks $\mathrm{D}$ and $\mathrm{E}$ were sprayed after the outbreak was established and $\mathrm{F}$ was not. For Blocks A, B and C, A was sprayed after the budworm infestation began and trees were damaged, B was sprayed before the budworm caused severe defoliation, and $\mathrm{C}$ was unsprayed. Combing 
these results in theory should permit a comparison of the effects of spraying pre-emptively reactive spraying, and not spraying at all.

\begin{tabular}{|l|c|c|c|c|c|c|c|}
\hline \multicolumn{7}{|c|}{ Table 3. Measured Defoliation Levels in Test Blocks } \\
\hline Block & 1990 & 1991 & 1992 & 1993 & 1994 & 1995 & 1996 \\
\hline A & S & S & O & O & O & O & M \\
\hline B & M & O & O & O & O & O & O \\
\hline C & M & O & O & O & S & M & O \\
\hline D & S & M & O & O & M & O & M \\
\hline E & S & M & O & O & M & O & M \\
\hline F & S & S & S & S & S & O & M \\
\hline
\end{tabular}

$\mathrm{O}=$ less than $35 \%$ defoliation; $\mathrm{M}=355$ to $70 \%$ defoliation; $\mathrm{S}=$ greater than $70 \%$ defoliation

The procedures outlined in the previous section provide information on what the volume should be for a given SI. However, growth in the presence of budworm is likely to be different. Volney and Watson (1996) analyze the actual annual growth by stem analysis of 96 trees. Growth was compared relative to a base year, 1988, when the budworm infestation was assumed to have started in the area. To summarize, in all of the blocks, 4 trees from each of the 4 plots were felled in 1995, 6 years after the start of infestation and 4-5 years after spraying. The growth rings were analyzed as outlined in Volney and Watson (1996) giving data on the relative annual increment. This annual growth is relative to the base year of 1988 , which was arbitrarily given a value of 1 . Note that this procedure provides information on the actual annual growth during a portion of the budworm outbreak, 1988-1994.

Table 4 shows the average values for the blocks in the 6 years preceding and following the infestation year of 1988. The measures shown in Table 4 are called the relative annual volume increment. Thus, normal or expected growth levels in the trees in the absence of budworm involves the annual increment in volume growth relative to the base year of 1988. For example, the relative growth in 1990 would be: $\quad\left(\mathrm{Vol}_{90}-\mathrm{Vol}_{89}\right) /\left(\mathrm{Vol}_{88}-\mathrm{Vol}_{87}\right)$. 
One can see from these figures that the incremental change in volume relative growth is larger prior to the reference year (1988) than after it. This suggests that the budworm outbreak is affecting the rate of increase in volume (in addition to the increase in volume) in these stands. We took a conservative approach and did not account for this increase in growth rate after the outbreak began.

It is also evident that the growth rate in the unsprayed block F shows no sign of recovery and the growth in the stand badly damaged before spraying commenced (A) continued to detriorate until 1994. Again a conservative approach was adopted: a value close to the mean for the years 1989 to 1994 was used in comparisons.

In order to calculate the total damage that occurred over the duration of the outbreak, the length of the infestation, and the assumed growth during the time following the measured period, must be hypothesized. The trees showed signs of previous infestations. In particular, nearly all of the 96 felled trees showed signs of an outbreak that started approximately in 1940, and lasted for 18 to 20 years. This outbreak was confirmed by studies in the Wabasca River area to the east (Stevenson, unpubl.). During the 1940-1960 outbreak the average incremental growth was 0.5 of the growth before the outbreak. While there was some annual variation, this average was consistent for all of the trees measured and approaches the value of 0.55 (Table 4) we observed for the earlier part of the current outbreak. 


\begin{tabular}{|c|c|c|c|c|c|c|c|c|c|}
\hline \multirow{2}{*}{ Year } & \multicolumn{9}{|c|}{ Actual Measures } \\
\hline & A & \multicolumn{2}{|c|}{ B } & $\mathrm{C}$ & \multicolumn{2}{|c|}{$\mathrm{D}$} & \multicolumn{2}{|c|}{$\mathrm{E}$} & $\mathrm{F}$ \\
\hline 1983 & 0.68 & \multicolumn{2}{|c|}{0.67} & 0.65 & \multicolumn{2}{|c|}{0.73} & \multicolumn{2}{|c|}{0.88} & 0.81 \\
\hline 1984 & 0.86 & \multicolumn{2}{|c|}{0.86} & 0.95 & \multicolumn{2}{|c|}{0.97} & \multicolumn{2}{|c|}{1.07} & 1.10 \\
\hline 1985 & 0.68 & \multicolumn{2}{|c|}{0.75} & 0.73 & \multicolumn{2}{|c|}{0.66} & \multicolumn{2}{|c|}{0.78} & 0.63 \\
\hline 1986 & 0.90 & \multicolumn{2}{|c|}{0.86} & 0.81 & \multicolumn{2}{|c|}{0.83} & \multicolumn{2}{|c|}{0.87} & 0.89 \\
\hline 1987 & 1.01 & \multicolumn{2}{|c|}{0.98} & 0.98 & \multicolumn{2}{|c|}{0.95} & \multicolumn{2}{|c|}{.098} & 1.04 \\
\hline 1988 & 1.00 & \multicolumn{2}{|c|}{1.00} & 1.00 & \multicolumn{2}{|c|}{1.00} & \multicolumn{2}{|c|}{1.00} & 1.00 \\
\hline 1989 & 0.99 & \multicolumn{2}{|c|}{0.95} & 1.10 & \multicolumn{2}{|c|}{0.98} & \multicolumn{2}{|c|}{1.03} & 1.00 \\
\hline 1990 & 0.80 & \multicolumn{2}{|c|}{1.03} & 1.20 & \multicolumn{2}{|c|}{0.86} & \multicolumn{2}{|c|}{0.95} & 0.92 \\
\hline 1991 & 0.43 & \multicolumn{2}{|c|}{0.87} & 0.93 & \multicolumn{2}{|c|}{0.59} & \multicolumn{2}{|c|}{0.73} & 0.55 \\
\hline 1992 & 0.24 & \multicolumn{2}{|c|}{0.83} & 0.81 & \multicolumn{2}{|c|}{0.43} & & & 0.41 \\
\hline 1993 & 0.19 & & 79 & 0.51 & 0. & & & & 0.23 \\
\hline 1994 & 0.35 & & 94 & 0.76 & 0 . & & & & 0.20 \\
\hline '89-94 mean & 0.51 & & & 0.80 & 0 . & & & & 0.55 \\
\hline & & & & Hypoth & al Mea & ures & & & \\
\hline & & & Contr & C) or 1 & Control & $(N C)$ & ptions & & \\
\hline & & $\mathrm{C}$ & $\mathrm{NC}$ & & $\mathrm{C}$ & $\mathrm{NC}$ & $\mathrm{C}$ & $\mathrm{NC}$ & \\
\hline 1995 & & & & & & & & & \\
\hline$\cdot$ & & 0.80 & 0.65 & & 0.65 & 0.5 & 0.65 & 0.5 & \\
\hline 2006 & & & & & & & & & \\
\hline
\end{tabular}

Based on these observations we postulated an 18 year outbreak which would take the present case from 1988 to 2006 . Given that no action was taken in 1940 , we also postulated that in the no-spray case, the relative incremental growth would be 0.5 in each of the years 1994 to 
2006. The effect of spraying was postulated to raise this relative annual increment to 0.65 in each of the years to the end of the outbreak. The former estimate is based on the ratio of volume increase exhibited during the 1940-1960 outbreak. The latter was obtained from a comparison of the affected growth between the unsprayed and sprayed stands over the 6 measured years. Thus, for experiment 1 incremental growth of volume in Blocks $\mathrm{D}$ and $\mathrm{E}$ was projected at a relative growth rate (with the 1988 rate $=1.00$ ) of 0.5 where unprotected and 0.65 with protection (Table 4). For experiment 2 , the relative incremental growth of volume in Block B was projected at 0.65 and 0.8 . These latter estimates were chosen to: 1) provide a comparison with the 0.65 relative annual increment in experiment 1 ; and 2) the 0.80 was chosen to represent an improvement in the volume change as a result of spraying. We will show that these estimates for both experiments are very conservative and will serve to make an analysis of the costs and benefits of spraying more moderate by underestimating the difference in growth between protected and unprotected stands.

\section{Analysis of increased mortality from budworm}

Increased mortality is also a known effect of outbreaks, and this is examined in the second scenario for each experiment beyond the observation period (i.e. to rotation age). To assess the effect of increased mortality caused by the insect, calculation of reduced numbers of stems was carried out separately for each experiment. The increased mortality was projected beginning in 1990. Mortality rates were calculated from a combination of literature reviews, and work by Volney on jack pine in Saskatchewan. The assumptions for the mortality function were: during a year of light infestation no increase in the background mortality was projected; for moderate infestation, the level is assumed to be double the normal rate; and for a severe infestation, mortality was assumed to be 5 times the normal rate.

When mortality was assumed to occur, the growth of surviving trees was assumed to be 0.65 (relative to 1988 rates) when stands were protected and declines to 0.40 in un-protected stands. For the projected outbreak, the level of infestation was assumed to be moderate for the 12 years of 1994 to 2006. This means we calculated mortality to be two times the background 
normal for each of these 12 years. This is true for our calculations of Block D and E, and scenario 1 of Block B. Block B was subjected to mortality rates evident when defoliation was light, in the case of pre-emptive spraying.

Once the infestation ends (year 2006), we return growth to normal and use the growth and yield tables to determine what the volume of the stand would be at rotation age. Thus, this procedure will show the effect of the reduced growth (and or increased mortality) during the outbreak on the final volume at rotation. For this, we calculated what the rotation volume would be with and without increased mortality in each experiment. This volume was then located in the growth and yield tables and the corresponding age was noted. This age was then subtracted from the age of the stand at the end of the outbreak, inserted into the breast height age equation at the age equal to the age at the outbreak, and all subsequent breast height age formulas to the end of the rotation. Volume was then estimated using the equations computed in the usual way. To illustrate, Block D would be 84 years old in 2006, and in the presence of an 18 year budworm outbreak with added mortality would have a stand volume of $179.93 \mathrm{~m}^{3} / \mathrm{ha}$. Locating this volume on the normal growth and yield tables, we note that this volume would have been achieved at age 60 in the absence of budworm. Thus during the 18 years of the outbreak, the stand lost 24 years of growth.

\section{Cost Benefit Analyses}

Based on a review of the literature we could find no cost benefit analyses of pest control measures in Canada at the stand level. Given that the outputs from the experiments described above will provide volume based measures of the success of control actions, it is possible to compare the economic value of the changes in volume with the costs of the control measures. A number of issues must be addressed in this comparison, however.

The first is that the costs will be incurred in the short term, but often the benefits achieved will not be gained for some time, specifically when the stand is harvested. Thus, it is necessary to bring all costs and benefits into the same time period (e.g. present values) in order to make a valid comparison. This procedure is called discounting and involves the selection of an interest 
rate. This is a controversial subject largely because most investments in forest pest control measures are made with public funds. We chose to discount costs and benefits back to the year that the control measures were enacted, 1990. Based on the work of Heaps and Pratt (1989) a discount rate of $4 \%$ was chosen. They recommend rates of 3-5\% for silvicultural investments using public funds. Furthermore, cost benefit analysis of pest management methods in B.C. (Deloitte and Touche 1992), which was subject to "expert" review, also used 4\%, and Canham (1986) report that the US Forest Service uses a similar rate..

A second issue is the value of timber harvested and the costs of harvesting timber at a site. Conversations with Manning Diversified personnel suggest a gross value of approximately $\$ 100.00 \mathrm{~m}^{3}$ of standing timber. This value is assumed to be constant over time. However, this timber value does not include harvesting costs. These are highly variable and generally unknown at the stand level. However, the cost of harvesting will be incurred whether or not the outbreak occurs, and at the same rotation age, and so is not included in the economic analysis.

A third issue are the costs of the budworm control methods. These were estimated using the actual applications outlined in Table 1. In conversations with LFS personnel (S. Ranasinghe) the average cost of spraying was $\$ 12.0685$ per hectare per application, with the normal procedure being two applications. In the experiments described in this report, the normal procedures were used with two applications of BTK in 1990 and in some cases additional applications in 1991 (Table 1).

We calculate net present benefits for two scenarios. First is a short term benefit cost ratio which involves only the changes in volume to 1994 . The benefits of the spray were estimated using only the measured tree ring data multiplied by the $\$ 100.00$ value of standing timber. The costs of the spraying was determined proportional to the application rates, and in the case of 1991 spraying, discounted at $4.0 \%$ back to 1990 .

To compare the effect of spraying to not spraying, first the difference in relative volume growth between the sprayed blocks ( $\mathrm{D}$ and $\mathrm{E}$ ) and the control (block F) was obtained. Next, the 
measured volume growth in $\mathrm{D}$ and $\mathrm{E}$ was compared to what it would have been in the absence of spraying; in other words if the growth had been like F. For example, suppose the relative growth in the sprayed blocks was $90 \%$ of pre-outbreak levels, and in the unsprayed areas $85 \%$ of preoutbreak growth rate. Comparing the $90 \%$ growth rate to the estimated $85 \%$ growth rate in the same block results in a 5\% difference which would be the volume saved by the spraying operation. The benefit (in dollars) of this 5\% difference in 1994 is then discounted back to the base year of 1990 when the costs of control were made. If the value of the benefit achieved is greater than the costs, then the operation is efficient in economic terms.

The second scenario involves a long term net present benefits. This involves an assessment of the efficiency of the program at the end of the rotation age, assuming no fires, further budworm outbreaks, no changes in fibre prices, and no further costs of management. In this scenario, the total block volume per hectare is estimated at the rotation age, the volume converted to economic values $\left(\$ 100 / \mathrm{m}^{3}\right)$, and the value is discounted back to the base year of 1990. The resulting economic benefits are then compared to the costs to see if the control operation is efficient.

\section{RESULTS}

\section{The Short Term Scenario}

\section{Experiment 1: The Young Stands with Reactive Control}

During the period 1988-1994 block volumes were assessed using the actual measures of relative incremental growth (Table 4) from felled trees. Resulting volumes are shown below in Table 5. The stand volume with and without budworm was calculated, along with the differences between the two. For the two blocks that were sprayed, Block D lost $17.96 \mathrm{~m}^{3} / \mathrm{ha}$, or $8 \%$ of normal volume, and block E lost 11.65 , or $6 \%$ of normal volume. The unsprayed block F lost $14.96 \mathrm{~m}^{3} / \mathrm{ha}$ or $11 \%$ of normal volume. To measure the effect of spray, we calculated what blocks $\mathrm{D}$ and $\mathrm{E}$ would have presumably lost without spraying (11\% of their normal), and compared it with actual losses. Block D would have lost an extra $7.91 \mathrm{~m}^{3} / \mathrm{ha}$, and Block E would have lost an extra $9.62 \mathrm{~m}^{3} / \mathrm{ha}$ if they had not been sprayed. 


\begin{tabular}{|l|c|l|l|}
\hline Table 5. Stand Volume ( $\left.\mathrm{m}^{3} / \mathrm{ha}\right)$ in Experiment 1 for the Short Term Scenario; 1988 to 1994. \\
\hline & \multicolumn{2}{|c|}{ Sprayed } & Unsprayed \\
\hline Block & $\mathrm{D}$ & $\mathrm{E}$ & \multicolumn{1}{c|}{$\mathrm{F}$} \\
\hline Expected 1994 volume (without damage) & 235.02 & 184.23 & 131.96 \\
\hline Observed 1994 volume (with budworm) & 217.08 & 172.58 & 117.00 \\
\hline Volume loss [Expected minus observed] & 17.96 & 11.65 & 14.96 \\
\hline Growth level as affected (\% of expected) & 92.00 & 94.00 & 89.00 \\
\hline Volume without spraying & 209.17 & 163.96 & 117.00 \\
\hline Volume saved by spraying & 7.91 & 9.62 & 0.00 \\
\hline
\end{tabular}

\section{Experiment 2: The Older Stands Comparing Reactive with Pre-emptive Control}

Recall that in this experiment two stands were used to compare a reactive regime which involved spraying after the outbreak had been established (Block A) with a pre-emptive control regime in which spraying occurred before the budworm outbreak was firmly established (Block B). For the reactive regime the volume loss was $5.17 \%$ of normal, while in the pre-emptive regime the loss was $1.54 \%$ (Table 6). If the outbreak had allowed to become established we estimate that Block B would have lost an extra $9.08 \mathrm{~m}^{3} / \mathrm{ha}$. This additional volume represents the savings in timber benefits gained during the period 1988-1994 as a result of the pre-emptive control regime. 
Table 6. Stand Volume $\left(\mathrm{m}^{3} / \mathrm{ha}\right)$ in Experiment 2 for the Short Term Scenario; 1988 to 1994.

\begin{tabular}{|l|c|c|}
\hline & \multicolumn{2}{|c|}{ Sprayed } \\
\hline & Reactive & Pre-emptive \\
\hline Block & A & B \\
\hline Expected 1994 volume (without damage) & 345.96 & 250.05 \\
\hline Observed 1994 volume (with budworm) & 328.10 & 246.20 \\
\hline Volume loss [Expected minus observed] & 17.86 & 3.85 \\
\hline Growth level as affected (\% of expected) & 94.83 & 98.46 \\
\hline Volume without pre-emptive spraying & $\mathrm{n} / \mathrm{a}$ & 237.12 \\
\hline Volume saved by pre-emptive spraying & $\mathrm{n} / \mathrm{a}$ & 9.08 \\
\hline
\end{tabular}

\section{Long Term Scenario}

In order to capture the complete picture of the effect of budworm in the long term, changes in mortality must be considered in addition to the changes in growth of surviving trees. There are several studies on increased mortality in balsam fir and jack pine, but none for white spruce directly. We assumed that mortality rates in undamaged white spruce stands, based on an inspection of growth and yield tables, approach $0.1 \%$ annually. This value was incremented, as described above, depending on the level of defoliation.

The method of using the growth and yield tables must be altered when calculating the effect of added mortality. The usual procedure is to proceed in several steps from breast height age to stand volume. Stems per hectare is usually caluculated from a basal area equation which is based on volume. We wish to show the change in volume caused by a combination of reduced growth, and a reduction in stem numbers per hectare and so the usual series of steps must be reversed.

To calculate the mortality effect we started with the number of stems that would be present in the absence of budworm.. This was then adjusted for each year based on the 
defoliation level mentioned above. Previously, we mentioned the values used for individual tree relative annual growth, which can be used to obtain the individual tree volumes. These individual tree volumes were multiplied by the adjusted stem count to obtain the stand volume as affected by increased mortality from 1994 to the end of the outbreak in 2006, and to the end of the rotation period.

Experiment 1: Volume Changes to the End of the Outbreak and at Rotation Age.

We project the growth in Blocks $\mathrm{D}$ and $\mathrm{E}$ into the future using the methods outlined above. In this analysis we do not estimate volume changes for the control stand, F because it provided an indication of the difference between a spray versus no spray situation for the period 1988 to 1994 . Now we project this difference within the stands that had been sprayed.

Table 7 shows that there is still some volume loss due to budworm under the reactive spray regime in the young stands. However, it is less than it would have been if no spraying had occurred and the effect of considering additional mortality makes a difference. At rotation, the control measures in Block D saved about $8 \mathrm{~m}^{3} / \mathrm{ha}$ in the case with no added mortality, and about $29 \mathrm{~m}^{3} /$ ha if increased mortality is considered. For Block E, the control measures resulted in volume savings of $10 \mathrm{~m}^{3} /$ ha with no additional mortality and $11 \mathrm{~m}^{3} /$ ha with additional mortality. Note that the volumes saved by spraying are lower at the end of the rotation than they were at the end of the outbreak (Table 7). The reason for this is that the stand has time to regrow some of the lost volume and the rate of growth will be higher in the affected stand than the normal since the rate is partially dependent on age (young stands grow faster than older stands). We also assumed that the damaged stands would recover at a rate corresponding to that of a young stand and that their growth rates had not been compromised by the outbreak. This can be seen in Figures 1 and 2 where the cumulative change in volume in these stands over time under the various scenarios are shown. 
Table 7. Stand Volumes $\left(\mathrm{m}^{3} / \mathrm{ha}\right)$ at the End of the Outbreak and at Rotation Age

\begin{tabular}{|c|c|c|c|c|c|}
\hline & \multirow{2}{*}{ Normal } & \multicolumn{2}{|c|}{ Without added mortality } & \multicolumn{2}{|c|}{ With mortality } \\
\hline & & Spray & No spray & Spray & No Spray \\
\hline \multicolumn{6}{|c|}{ Block D } \\
\hline At end of outbreak & 284.13 & 237.29 & 224.18 & 211.56 & 191.72 \\
\hline Volume saved by spraying & & \multicolumn{2}{|c|}{$13.11 \mathrm{~m}^{3} / \mathrm{ha}$} & \multicolumn{2}{|c|}{$19.84 \mathrm{~m}^{3} / \mathrm{ha}$} \\
\hline At rotation age & 328.02 & 284.20 & 276.20 & 242.84 & 229.72 \\
\hline Volume saved by spraying & & \multicolumn{2}{|c|}{$8.00 \mathrm{~m}^{3} / \mathrm{ha}$} & \multicolumn{2}{|c|}{$13.12 \mathrm{~m}^{3} / \mathrm{ha}$} \\
\hline \multicolumn{6}{|c|}{ Block E } \\
\hline At end of outbreak & 236.13 & 192.45 & 180.10 & 166.34 & 152.60 \\
\hline Volume saved by spraying & & \multicolumn{2}{|c|}{$12.35 \mathrm{~m}^{3} / \mathrm{ha}$} & \multicolumn{2}{|c|}{$13.74 \mathrm{~m}^{3} / \mathrm{ha}$} \\
\hline At rotation age & 318.99 & 282.96 & 272.50 & 261.81 & 250.84 \\
\hline Volume saved by spraying & & \multicolumn{2}{|c|}{$10.46 \mathrm{~m}^{3} / \mathrm{ha}$} & \multicolumn{2}{|c|}{$10.97 \mathrm{~m}^{3} / \mathrm{ha}$} \\
\hline
\end{tabular}


Figure 1. Volumes in Block D under different spray regimes.

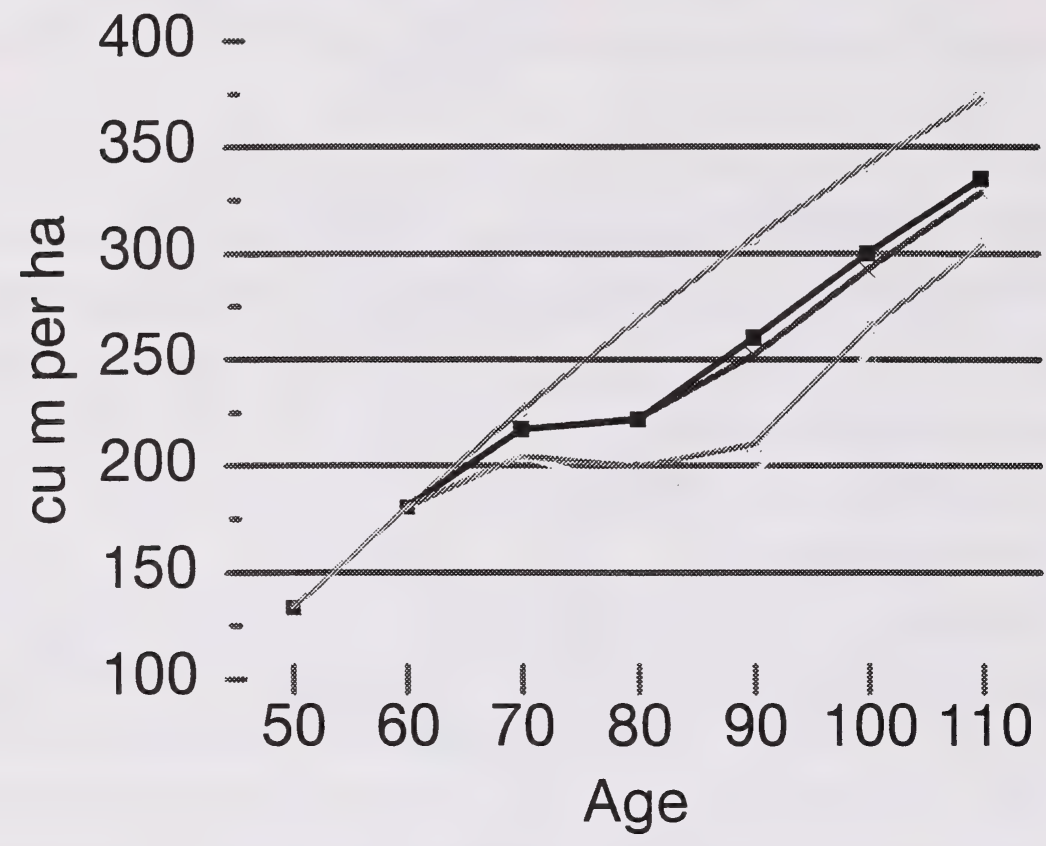

* unsprayed

nowal normal

sprayed

unsprayed-mortality sprayed-mortality 
Figure 2. Volumes in Block E under different spray regimes.

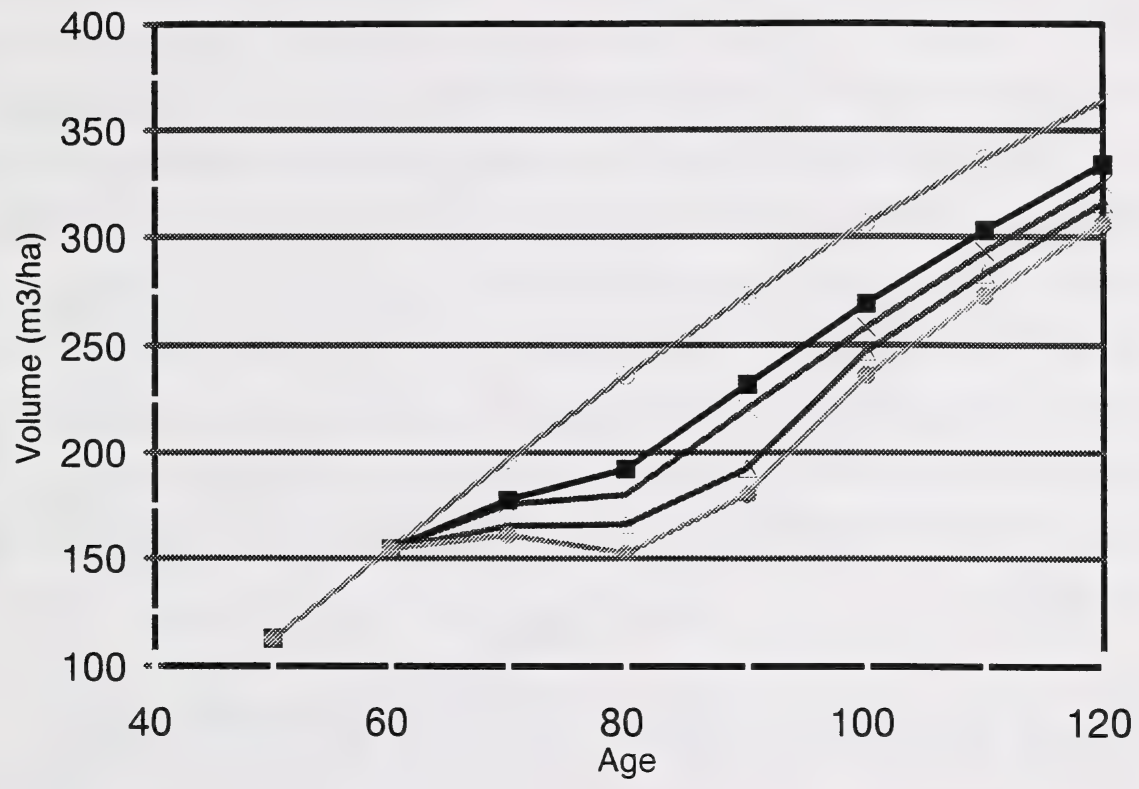

*-Infestation; no spray $\quad$ Normal growth

- Infestation with spray $\triangle$ mortality sprayed

mortality - not sprayed 


\section{Experiment 2: Volume Changes to the End of the Outbreak and at Rotation Age}

In this section the analysis will concentrate on Block B the pre-emptively sprayed plot. Here it is necessary to show what the stand volume would be in the future under both the reactive and pre-emptive regimes. Given that the pre-emptive regime successfully prevented the outbreak from becoming established (Table 6), we postulate that there would be no increase in mortality using this control regime. In Block B, the pre-emptive control regime would save about $7 \mathrm{~m}^{3} / \mathrm{ha}$ by the time the 18 years of the outbreak had passed, and just under $5 \mathrm{~m}^{3} /$ ha by rotation (Table 8 ). These results also identify a volume saved at rotation that is lower than that at the end of the outbreak. As in experiment 1 the reason for this is the same, as we assume recovery rates following outbreaks that correspond to stands growing as though they were several years younger. This is shown in Figure 3 where the lines of total volume gradually converge after the outbreak period.

Table 8. Stand Volumes $\left(\mathrm{m}^{3} / \mathrm{ha}\right)$ at the End of the Outbreak and at Rotation Age: Block B.

\begin{tabular}{|c|c|c|c|c|}
\hline \multirow[t]{3}{*}{ Time Period } & \multirow[t]{3}{*}{ Normal } & \multicolumn{3}{|c|}{ Spray regime } \\
\hline & & \multicolumn{2}{|c|}{ Without added mortality } & \multirow{2}{*}{$\frac{\text { With added mortality }}{\text { Reactive }}$} \\
\hline & & $\begin{array}{l}\text { Pre- } \\
\text { emptive }\end{array}$ & Reactive & \\
\hline End of infestation & 286.84 & 268.07 & 259.51 & 256.15 \\
\hline $\begin{array}{l}\text { Volume saved by pre- } \\
\text { emptive spraying }\end{array}$ & & \multicolumn{2}{|c|}{8.56} & \\
\hline Rotation age & 309.32 & 285.00 & 280.35 & 277.10 \\
\hline $\begin{array}{l}\text { Volume saved by pre- } \\
\text { emptive spraying }\end{array}$ & & \multicolumn{2}{|c|}{4.65} & 7.90 \\
\hline
\end{tabular}


Figure 3. Volumes in Block B under different spray regimes.

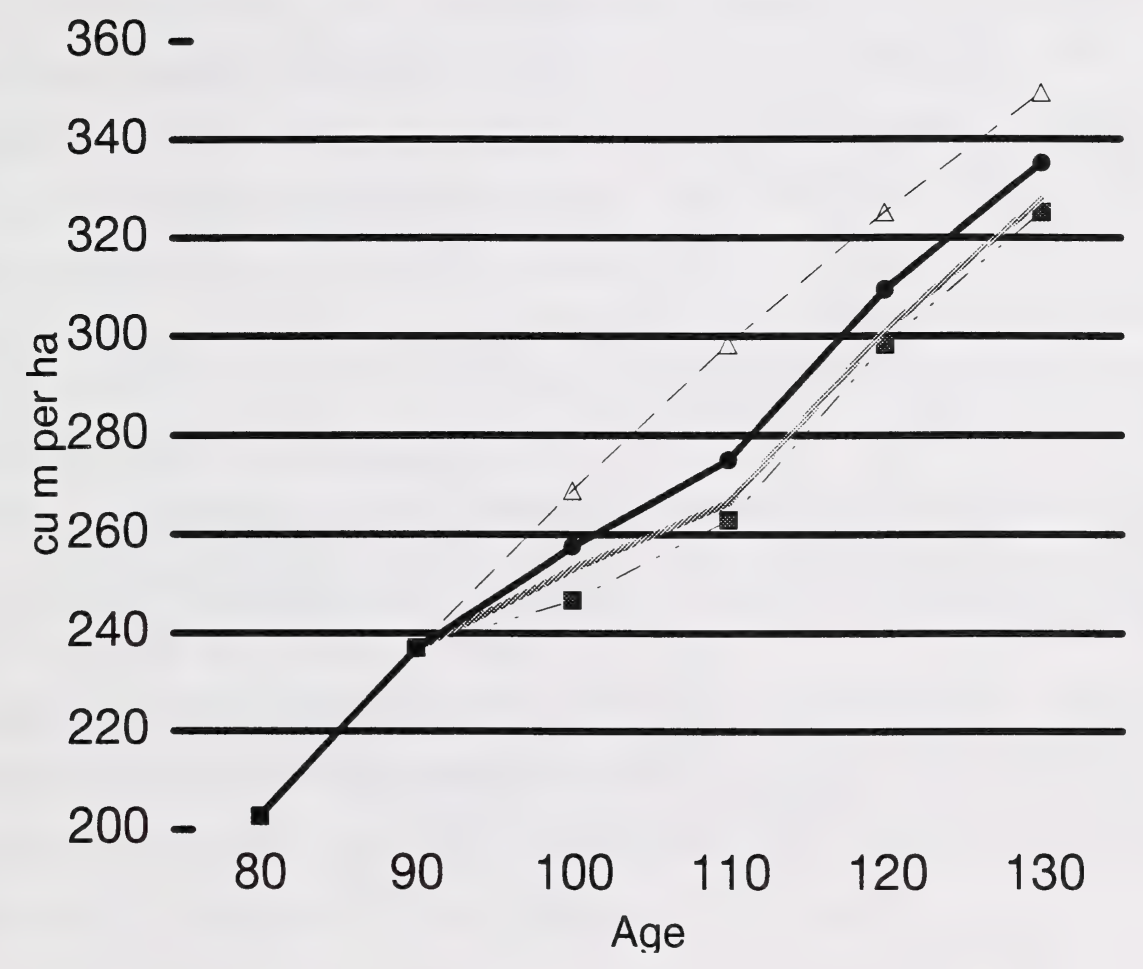

mortality -reactive reactive spray

- pre-emptive spray $\quad$ - normal 


\section{Benefit Cost Analysis}

\section{Reactive Spraying on Young Stands}

Recall from Table 4 that the amount of volume saved by reactive spraying was $7.91 \mathrm{~m}^{3} / \mathrm{ha}$ in Block D and $9.62 \mathrm{~m}^{3} / \mathrm{ha}$ in plot $\mathrm{E}$. When these blocks reach rotation age, these volume savings will be affected by the assumptions of increased mortality. Without increased mortality, spraying saves an estimated $8.00 \mathrm{~m}^{3} / \mathrm{ha}$ in Block $\mathrm{D}$, and $10.5 \mathrm{~m}^{3} / \mathrm{ha}$ in Block E. With added mortality, spraying saves $29.10 \mathrm{~m}^{3} / \mathrm{ha}$ in Block D and $11.00 \mathrm{~m}^{3} /$ ha in Block $E$.

With knowledge of the costs and benefits as outlined in the methods these volumes were converted to economic values. Table 9 outlines the results of these conversions and shows the net present benefits provided by the control measures over the period 1988-1994 and also at rotation age. In all scenarios, the net present benefits are greater than 0 , suggesting that the control measures are justified on economic grounds. Over the short term period (1988-1994) for which we have accurate measures of the volume losses, the net present benefits are large. At rotation, which is the time at which the forest manager harvests the stand and receives any benefits, these values are reduced. As expected, increased mortality could play a large role in assessing the net present benefits. However, even without increased mortality as a result of budworm outbreaks, the control measures are worthwhile. 


\begin{tabular}{|l|c|c|}
\hline \multicolumn{3}{|c|}{ Table 9. The Benefits and Costs of Reactive Spraying on Young Stands. } \\
\hline Block & $\mathrm{D}$ & $\mathrm{E}$ \\
\hline Volume saved by spraying & $7.91 \mathrm{~m}^{3} / \mathrm{ha}$ & $9.62 \mathrm{~m} / \mathrm{ha}$ \\
\hline Value $(\$ 1994)$ of saved volume & $\$ 791$ & $\$ 962$ \\
\hline Discounted benefit/ha $(\$ 1990)$ of reactive control & $\$ 650.14$ & $\$ 790.70$ \\
\hline Costs/ha of control regime $(\$ 1990)$ & $\$ 74.51$ & $\$ 52.20$ \\
\hline Present net benefit/ha $(\$ 1990)$ (benefits minus costs) & $\$ 575.64$ & $\$ 738.50$ \\
\hline
\end{tabular}

\begin{tabular}{|l|c|c|c|c|}
\hline \multicolumn{5}{|c|}{ At estimated rotation } \\
\hline & \multicolumn{2}{|c|}{ No increased mortality } & \multicolumn{2}{c|}{ Increased mortality } \\
\hline Block & D & E & D & E \\
\hline Volume saved by spraying $\left(\mathrm{m}^{3} / \mathrm{ha}\right)$ & 8.00 & 10.46 & 13.12 & 10.97 \\
\hline Net present benefit/ha of control $(\$ 1990)$ & $\$ 182.02$ & $\$ 149.23$ & $\$ 346.19$ & $\$ 159.06$ \\
\hline
\end{tabular}

Regarding the efficiency of reactive versus pre-emptive spraying, similar calculations was made for block B. Table 10 provides the results. Here the net present benefits are also positive but are considerably smaller than those for the younger stands. This is probably due to the older age of the stands in this experiment and is particularly evident at rotation. 


\begin{tabular}{|l|c|}
\hline \multicolumn{2}{|c|}{ Table 10. Net Present Benefits of Pre-emptive Control Regimes } \\
\hline & Without mortality increase \\
\hline Block & B \\
\hline Volume $\left(\mathrm{m}^{3} / \mathrm{ha}\right)$ saved by spraying & 9.08 \\
\hline Present benefit/ha $(\$ 1994)$ of pre-emptive control & $\$ 908.00$ \\
\hline Discounted benefit/ha $(\$ 1990)$ of pre-emptive control & $\$ 749.88$ \\
\hline Costs/ha of control regime $(\$ 1990)$ & $\$ 92.81$ \\
\hline Present net benefit/ha $(\$ 1990)$ (s benefits minus costs) & $\$ 657.07$ \\
\hline
\end{tabular}

\begin{tabular}{|l|c|c|}
\hline \multicolumn{3}{|c|}{ At estimated rotation } \\
\hline & No increased mortality & Increased Mortality \\
\hline Volume saved by spraying $\left(\mathrm{m}^{3} / \mathrm{ha}\right)$ & 4.65 & 7.90 \\
\hline Net present benefit/ha of control $(\$ 1990)$ & $\$ 85.19$ & $\$ 207.10$ \\
\hline
\end{tabular}

\section{DISCUSSION}

Our findings suggest that spruce budworm outbreaks have negative impacts on the growth of white spruce stands in the study area. These impacts on stand volumes were assessed with some very conservative assumptions on growth and yield. Budworm defoliation in the younger stands examined reduced volume growth by $11 \%$ of normal. However, the use of BTK had a significant effect in depressing these negative effects. In two replications of spraying BTK in young stands (Blocks D, E) where the outbreak was established, this volume reduction decreased to $6 \%$ and $8 \%$ of normal respectively. In an older stand (Block A) where a similar BTK application regime was used, a reduction of $5.17 \%$ of normal was observed. The success of these control measures, however, raises further questions about the use of different application regimes and the economic efficiency of the BTK control measures.

A second BTK application regime was examined in an additional experiment. In this 
case, BTK was applied to an older stand (Block B) before the budworm outbreak became established. This pre-emptive control strategy resulted in an even further reduction in the decrease of volume, in this case to $1.54 \%$ of normal. Thus, in older stands a reactive control strategy, while effective, would not achieve the same level of success as a pre-emptive strategy. However, whether pre-emptive control strategies work on younger stands remains an open question. Further research will be required to address this issue. Simulating the effects of a preemptive spray using the growth and yield formulas on Blocks D and $\mathrm{E}$ (by using the same relative annual increment of 0.8 as used in Block B) does show a very strong reduction in loss. Calculation shows that the stand volumes would be 303 and $296 \mathrm{~m}^{3} / \mathrm{ha}$ respectively. Under the reactive spray regimes they would be 284 and 283 if we assume no elevated mortality, and 243 and 261 respectively, with mortality, (Table 7). This strategy, applied to young stands, can save a potential 30 to $60 \mathrm{~m}^{3} / \mathrm{ha}$ under a worst case scenario.

We found that the costs of the BTK applications were less than the benefits in constant dollar terms. This difference was consistent over the short term period in which actual measurements where conducted (1988-1994), and over a longer term period to an estimated rotation age of the stands. A forest manager using current knowledge of the costs and timber values who decides to control a budworm outbreak in young or old stands would appear to making the correct decision. In older stands, of course, the benefits of the pre-emptive policy are larger than those for the reactive policy. These findings suggest that the use of BTK to control spruce budworm outbreaks in white spruce stands is economically efficient when only timber values are considered. Furthermore, we emphasize that all the assessments of volume changes and mortality are conservative.

The effect of spruce budworm outbreaks and their control on non-timber values remain an important issue. Examining linkages between budworms, BTK control measures, and nontimber goods and services is difficult. What is required is: 1) an inventory of non-timber goods and services provided by forest stands where outbreaks occur; 2) knowledge of the impacts of budworm outbreaks on these goods and services; 3 ) knowledge of the impacts of the budworm control measures on these goods and services; and 4) a process that collects information on these 
impacts that allows conversion to economic values so they can be incorporated into the benefit cost analysis.

First, any inventory of non-timber goods and services should include ecological services, marketed non-timber goods (e.g. mushrooms), and non-marketed goods and services such as aesthetic values, recreation, and passive use values ${ }^{1}$. Ecological services, while important, are exceedingly difficult to measure in economic terms and thus will be virtually impossible to assess. In many cases an inventory of non-timber goods and services will reveal few direct linkages between people and the stands due to remoteness, or these linkages will not involve enough individuals to have a significant impact on the benefits and costs. Thus, more indirect linkages which involve aesthetic and passive use values may have to be examined.

Second, in order to assess the impacts of forest pests and BTK on non-timber values considerable research remains to be done. A literature review reported in the previous year (Volney and Watson 1996) revealed few studies in this area. Furthermore, many of these studies were dated and have not used more recent developments in economic modeling. On the other hand, significant effort has been expended on the impacts of pests on aesthetic or scenic values of the forest. However, few, if any, of these have been conducted in Canada. The impacts of budworm on aesthetic values remains fertile ground for future research.

\section{FURTHER RESEARCH}

In the next phase of this study we propose to complete the examination of some of the impacts of budworm on non-timber values. A preliminary inventory of some of the non-timber services provided by forest in the Hawk Hills area was completed (see Appendix B). This inventory suggests that it will be difficult to assess the impacts of budworm outbreaks on these values for the reasons stated above. Thus, we propose to examine impacts of budworm on the visual and aesthetic features of the

${ }^{1}$ These latter values include such things as the values of the existence of various species, option values, and bequest values. See Adamowicz (1991) for a review of these concepts. 
forests. This will require continuing field work to collect photographs of damaged and undamaged stands as well as some additional plot measurements to calibrate the visual qualities. We propose to utilize the Scenic Beauty Method (Daniel and Boster 1976) in concert with econometric techniques. A very preliminary draft of the survey instrument, and outline of the method is contained in Appendix C. To assist with this endeavour, we have invited Dr Wolfgang Haider from the Centre for Northern Forest Ecosystem Research to join the research team. Dr. Haider is a national expert on scenic quality of forests in Canada and has agreed to assist us with this project.

\section{LITERATURE CITED}

Adamowicz, W.L. 1991. The valuation of environmental amenities. Canadian Journal of Agricultural Economics 39(4):609-618.

Alberta Forest Service. 1985. Alberta phase 3 forest inventory: yield tables for unmanaged stands. Report \# Dept 60a, Alberta Forestry, Lands, and Wildlife. Edmonton.

Canham, H.O. 1986. Break-even benefit/cost model: A useful tool for forestry decision-making. Northern Journal of Applied Forestry 3:14-16.

Daniel, T.C. and R.S. Boster. 1976. Measuring landscape esthetics: The scenic beauty estimation method. USDA Forest Service Research Paper, RM-167, Rocky Mountain Forest and Range Experiment Station, Fort Collins, $\mathrm{CO}$.

Deloitte \& Touche Management Consultants. 1992. Economics assessment of western spruce budworm control in B.C. forests. Report prepared for B.C. Ministry of Forests, Silviculture Branch, Victoria, B.C.

Heaps, T. and B. Pratt. 1989. The social discount rate for silvicultural investments. Paper 
prepared for the B.C. Ministry of Forests, Industry Development and Marketing Branch, Victoria, B.C.

Huang, S. 1994a. Individual tree volume estimation procedures for Alberta: methods of formulation and statistical foundations. Alberta Environmental Protection. Land and Forest Services, Forest Management Division, Edmonton

Huang, S. 1994b. Ecologically based Individual tree volume tables for White Spruce (Picea glauca. (Moench) Voss). Alberta Environmental Protection. Land and Forest Services, Forest Management Division, Edmonton

MacLean, D.A. and T.A. Erdle. 1984. A method to determine effects of spruce budworm on stand yield and wood supply projections for New Brunswick. For Chron 60:167-173.

Stevenson, R.E. The spruce budworm in northern Alberta: with emphasios on the Wabasca outbreak. Unpublished Report.

Volney, W.J.A. 1990. Hawk hills spruce budworm project report. Unpublished report. Forestry Canada, Northern Forestry Center, Edmonton, Alberta

Volney, W.J.A. 1992. Hawk hills spruce budworm project 1991 report. Unpublished report. Forestry Canada, Northern Forestry Center, Edmonton, Alberta

Volney, W.J.A. \& D.O. Watson 1996. Assessment of spruce budworm impacts in Hawk Hills management area; A progress report. Unpublished report. Forestry Canada, Northern Forestry Center, Edmonton, Alberta. 


\section{APPENDIX A}

This appendix includes the equations used in the growth and yield tables to calculate the stand volumes in the various test blocks. The equations do not change between the blocks, though the site index they are based on will. These equations are taken from AFS (1985). However, it should be noted that due to typographical errors, several of these are incorrect in AFS (1985).

Site Index (SI)

To calculate the site index (normally done at age 50), the stand must be measured for $\mathrm{dbH}$, and an average height calculated. This site specific height along with the stump age are used in the SI formula.

$$
\text { Height (HT) is: } \quad \ln H T=a+\frac{b}{(d b H+1)}
$$

where $\mathrm{a}$ and $\mathrm{b}$ are region speciric coefficients for white spruce. This is used in the SI calculation as follows:

$$
\begin{aligned}
& S I 50=21.7888+(0.5564 X H T)-\left(0.9144 X(\ln (H T))^{2}\right) \\
& -(4.1848 X \ln (\text { STAGE }))-(45.2407 / S T A G E)+(37.0182 X(\text { HT/STAGE }))
\end{aligned}
$$

where STAGE is the stump age, measured from felled trees 1.3 meters from ground level.

The equations to arrive at the required values of stand total volume, and number of stems per hectare follow a progression as follows; a series of 3 age equations, from actual age to stump age to breast height age; then two height equations, the site height and top height, and volume. Stems per hectare series starts with the volumes values, through a basal area equation and a diameter equation to arrive at the number of trees.

Total age: usually listed in steps of 10 years.

Y2STMP: the years of growth needed to reach stump height of $0.3 \mathrm{~m}$.

$$
\mathrm{Y} 2 \mathrm{STMP}=6.0
$$

YR2BH: the years of growth needed to reach breast height of $1.3 \mathrm{~m}$.

$$
\mathrm{YR} 2 \mathrm{BH}=\mathrm{Y} 2 \mathrm{STMP}+2.16+(110.76 / \mathrm{SI})
$$


SHT: Site height, which uses the SI and YR2BH

$$
: H T=1.3+\frac{(S I-1.3) X(1+\exp (9.6183-(1.4627 X \ln (50))-(1.2240 X \ln (S I-1.3))}{(1+\exp (9.6183-(1.4627 X \ln (Y R 2 B H))-(1.2240 X \ln (S I-1.3)))}
$$

TOPHT: top height, which progresses from the site height as follows

$$
\text { TOPHT }=1.3+\left(1.65 X(S H T-1.3)^{0.865}\right)
$$

VOLUME: The calculation of total stand volume uses the top height value

$$
\text { VOLUME }=1100 \times \frac{1-\exp (-.0675 X(\text { TOPHT }-1.3))}{1+(8.8862 X \exp (-.0675 X(\text { TOPHT }-1.3)))}
$$

The number of stems (NTREE) is calculated by first using the volume values in a basal area equation (BA), and the TOPHT values in a diameter equation $\mathrm{A}(\mathrm{QDIA})$.

$$
\begin{gathered}
B A=-1+\left(1.1356 \times(\text { VOLUME }+1)^{0.8626}\right) \\
\text { QDIA }=\left[-100.080+\ln \left(1-\frac{(\text { TOPHT }-1.3)}{45)}\right)\right]^{0.7115} \\
\text { NTREE }=\frac{B A}{0.00007854 \times Q D I A^{2}}
\end{gathered}
$$




\section{APPENDIX B}

This appendix contains a preliminary inventory of the non-timber assets of the forest in the Hawkhills study region, and the results of interviews with members of the surrounding communities. In order to judge the attraction of the area for recreation, the inventory includes features that are contained in a larger geographical region than the budworm study area. The assets are broken down into parks and recreational areas, wildlife use (consumptive and nonconsumptive), and other uses.

In overview, the park statistics, and interviews suggest that while the potential is strong, actual recreational use of the region is limited. The main recreational uses of the forest are hunting, both local and guided, and some camping in the parks. The hunting activities are mainly on the forest fringe, and along seismic cut lines. Fishing in the region is very limited, basically in the stocked lakes of parks, and along the Peace River. Random camping outside of the parks is either non-existent, or un-measured. Winter use for snow-mobiling is not common. The other main non-timber use of the forest is fur-trapping.

\section{Parks and Recreation areas}

There are two provincial parks and one campground within $25 \mathrm{~km}$ of the study area, and several others within $100 \mathrm{~km}$.

Twin Lakes Provincial Park, located north of the study area along Highway 35. It is a short distance off the highway, and across from a lodge of the same name. There are two very small lakes, that have been stocked with trout. Motorboats are not allowed on these lakes. There are 49 camping sites, with self-registration (pay), and firewood provided.

Regional parks personnel suggest that the park is mostly used by locals, as a place to go fishing with the children. Only about $20 \%$ of use is by non-local, off the highway traffic. Total use for the period April 1994 to Mar 1995 (latest available statistics) was 551 occupied campsite 
nights, with average group size of 3.1. The Jul/Aug 1994 period shows an occupancy rate on average of $12 \%$. For the same period, the day use figures show a total of 15,700 visits, with an average group size of 2.5. Historical statistics, dating back to 1987/89 show only small fluctuations within the camping nights, ranging from 482 to 591, but a steady and significant increase in day use, from 580 in $87 / 88$ to 2,075 in $91 / 92$, and 15,700 in $94 / 95$. The $94 / 95$ day use numbers are a $22 \%$ increase from the previous year.

Notikewan provincial park is a quite large, measuring nearly $20 \mathrm{~km}$ south to north, and 5 $\mathrm{km}$ east to west. Most of this area is not accessible by road, and the camping/picnic area has poor road access. The access is from Highway 35 near Hawk Hills, with first $20 \mathrm{~km}$ of gravel, then changing to dirt that seems to go through a farmers field. The park has a gate and office, but these are no longer manned. From the entry, the road goes down a long steep hill to the 19 sites in the campground, the picnic area, and the boat launch onto the Peace River. This park has very low use, with only 76 occupied campsite nights in 1994/95, and average group size of 3.6 The July/Aug occupancy rate was $3 \%$. Day use for the same period was 800 total party visits, with average group size of 2.6. These numbers are about half the equivalent visits for the late 1980's, where the average annual occupied campsite nights was 125 . Regional parks staff suggest the drop is due in large part to the road and hill having been intermittantly washed out where a culvert diverted a small stream. Even though repairs, and a new bigger culvert is said to solve this, it is thought that people either no longer trust the road in the park, or are unaware of the repairs. The hill would probably still be slippery in rainy weather. There is no structured boat launch, just a track to the shore. [Parks staff say they can't afford the $\$ 800 \mathrm{~K}$ necessary for a proper boat launch, and anything less just keeps washing away].

The use the park does get is mostly by local people, though it is listed in provincial parks guides and in the Alberta Wildlife viewing guide, with a mention of sandhill cranes, raptors and cavity nesting birds. The wildlife viewing guide also lists the presence of moose, black bear and grizzly bear.

The Hotchkiss campground is located where Highway 35 crosses the Hotchkiss River. 
There is no fee, and there are no designated camping sites. Use statistics are not keep for this area. Within the campground, there are cleared spots that appear to be used for camping, a central kitchen, and ball diamonds. Weekend and special tournaments would appear to be the main uses of this campground. It would not likely be attractive to traffic passing through the region.

There are other parks within $100 \mathrm{~km}$ of the study area, that may also provide accommodation for visitors to the study area, such as Queen Elizabeth park close to Grimshaw, or the Sulfur River campground near Dixonville. Information on these is not yet available.

\section{Wildlife use}

Visits related to wildlife may be broken down into two categories, non-consumptive (such as birdwatching), and consumptive (hunting and fishing). Within the consumptive category, a further division can be made into commercial (guided hunting and trapping), and noncommercial (personal hunting).

There is very little information on non-consumptive use of the forest in this area. Interviews revealed no organized clubs or activities, though there was mention of "one fellow who may do some bird watching". There have been no previous large-scale surveys of visitors that included a section on reason for visiting the area. A limited distribution survey was conducted for Notikewan park, that included a section on activities of visitors while in the park. Summary statistics for this survey are not available to the public.

Both segments of consumptive use would appear to be the major use of the forest in this region. This would include fishing and personal hunting as non-commercial, along with the commercial activities of guided hunting, and fur-trapping. For future work, it may be possible to obtain the particulars of hunting permits issued for the region, and conduct a survey of users, and economic statistics of fur sales for that activity. 
Fishing is not strong in the immediate area, and is not heavily engaged in. The best fishing is in the stocked lakes of Twin Lakes park, the confluence of the Notikewan and Peace Rivers in Notikewan park, and the Peace River in general. These areas would not be enough of an attraction to draw in non-local visitors.

Personal hunting is very strong among the local population. Interviews with various sources such as local fish and wildlife officers, parks staff, and town officials elicited comments such as "most of the males in town have a rifle and hunt". As well, due to recent restrictions placed on hunting seasons in other parts of the province that will not apply here, there may be a future influx of non-local Albertans to the region. The main species sought are bear, moose and geese, with the forest type not conducive to deer hunting. The hunting that is carried out only involves the forest fringe (roads and cut-lines), and the interface between forest and agricultural areas.

Guided hunting is well established in the area, with about 10 to 12 main operators, and perhaps others that operate from nearby (i.e. Peace River). As well, there are two commercial lodges within $50 \mathrm{~km}$ of the study area. Conversations with operators and clients suggest that the majority of clients are working class individuals or groups from the United States. One operator stated that he only advertises in one hunting magazine in the US, and that provides him with sufficient clients for his operation. This is probably an area where future growth is possible, given operators with the ambition to expand.

Trapping is well established in the area, with a strong local trappers associated. In general it is an activity for a secondary income, with another career (such as agriculture) providing the main income. Representatives of the association were unsure how a budworm infestation would affect their activities, but were willing to participate in further surveying or questioning of their opinions. They were more concerned about how the activities of the forest companies did affect their trapping. 
This category could include snowmobiling, collection of edible plants and berries, collection of materials for artisanal creations, or hiking. There is no information on any of these activities, with the possible exception of limited knowledge of snowmobiling. The town of Manning does have a snowmobile club. Interviews with various local people suggested that snowmobiling, to their knowledge, was more likely to be pursued on agricultural land than on forested land. 


\section{APPENDIX C}

This appendix outlines briefly the work required to further survey the value placed on the non-timber resources in the study region, including a description of the probable major sections that will be contained in the survey instrument.

At this preliminary stage, the suggested primary survey work will be the use of a Scenic Beauty Method slide show with focus groups in the local region. Representatives of groups previously interviewed have stated a willingness to participate in such focus groups. A representative sample at this stage would result from 4 to 6 focus groups of between 10 and 15 individuals. If the results of these focus groups shows that budworm defoliation has a strong influence on forest use then a larger sample population, and expanded methodology should be considered. The results of the inventory of non-timber forest resources show that the major uses are along the forest fringe, or from roadways, and as such this will be the focus of the picture collection activity.

\section{Scenic Beauty Method (SBM)}

This is a well developed procedure that measures the attractiveness of an area to users. The primary details of the method are outlined in Daniel and Boster (1976), and for over 15 years use of this or related methods has been a required part of forest management plans for the United States Forest Service. It can take two basic forms; 1) respondents are shown are series of slides of forested areas containing the detail of interest (budworm damage), and asked to rate the beauty of the scene on some scale (i.e. one to five), or 2) respondents are shown a series of pairs of slides and asking respondents which scene they prefer. In either case, the slide set contains a continuum of damage, from undamaged, to very heavily damaged. In this way, the effect of the damage on the perceptions of respondents, and whether there are specific crucial levels of damage that affect appreciation, can be calculated from pooling the results. For example, there may be a point such as $20 \%$ defoliation, where any further defoliation no longer lowers apprciation. If this was true, then efforts to stop infestation would be very important, but efforts to reduce infestation would not matter to respondents. 
The choice of scenes, and the comparability of vistas becomes very important in using the SBM. For example, if one scene had rocky outcrops, and another did not, the appreciation of the beauty of the rock may override any consideration of budworm damage. The work of collecting photos therefore will include careful measurement of all the added attributes of the scene, and slides will, in the final presentation, be selected so that only the budworm damage changes are important.

\section{Economic Valuation}

The most appropriate method to measure economic valuation is probably $\mathrm{CV}$ ( contingent valuation). Daniel et al (1989) ${ }^{2}$ have shown that $\mathrm{CV}$ and the SBM can be applied to the same series of slide with comparable results, and that the respondents are sensitive to the same variations in forest condition in both examinations.

$\mathrm{CV}$ is also a well accepted method of surveying, that involves asking people about their willingness to pay for specific environmental changes. For the purposes of this study, the questions would revolve around users willingness to pay for budworm control and/or changes in their use patterns in response to visible defoliation of the forest.

\section{Survey Instrument Outline}

This is a first stage outline of the instrument, and the final result is likely to contain many changes. However, there are certain features of a successful valuation survey that may change in specific detail, but are nearly always present. The outline below contains the sections that will be part of a printed questionnaire that should be completed in conjunction with the slide show presentation, with a portion to be completed before the slides, and a second portion immediately following the presentation.

\footnotetext{
${ }^{2}$ Daniel, T.C., Brown, T.C., King, D., Richards, M. and W.P. Stewart. 1989. Perceived Scenic Beauty and Contingent Valuation of Forest Campgrounds. For Sci 35(1):76090
} 
Part I Experience and history

Part II General preferences

Part III General knowledge

Part IV

Particulars
The initial section of the survey will ask respondents about the type of use they make of the forest in the region (i.e. hunting, hiking etc), their past use of the region, and their overall experience levels in their chosen activity.

This section will contain a series of statements, with respondents answering their level of agreement with the statement on a Likert scale (1 to 5). For example, the statement may be "Forests should be managed to meet the needs of as many people as possible", with the possible response ranging from "strongly disagree" to "strongly agree"

Questions in this section will relate to the knowledge of the budworm, and its control, as well as general forest management.

This section will ask personal information about the respondent in order to place them within well defined groups of society. This section will include (but is not limited to)questions on age, sex, family size, income, and participation in organizations (i.e. hunters groups, snowmobile clubs) 
National Library of Canada
Bibliotheque nationale du Canada

||||||||||||||||||||||||||||||||||||||||||||||||||||||||||||||||||

3 3286513570412 